Jordash Kiffiak

\title{
Responses in the Miracle Stories of the Gospels
}

\author{
Between Artistry and Inherited Tradition
}

[Die Reaktionen der Figuren in der Wundererzählungen der Evangelien. Zwischen Kunstfertigkeit und ererbter Tradition.]

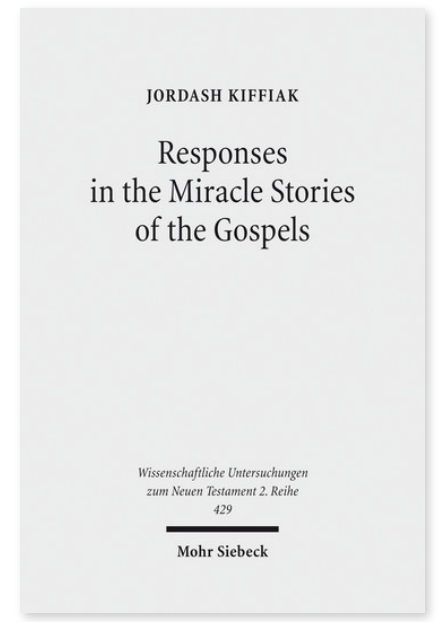

2017. XXIX, 817 Seiten. WUNT II 429

ISBN 978-3-16-154220-6

DOI 10.1628/978-3-16-154220-6

eBook PDF $174,00 €$

ISBN 978-3-16-154083-7

fadengeheftete Broschur $174,00 €$
Veröffentlicht auf Englisch.

Jordash Kiffiak untersucht erstmals ein allgegenwärtiges Motiv in den Wundergeschichten der Evangelien: die Darstellung der Worte, Gefühle und Handlungen, die durch Wunder hervorgerufen werden. Nach der vorherrschenden Forschungsmeinung dienen die Reaktionen der Figuren auf das Wunder dazu, den Wundertäter in ein positives Licht zu rücken. Demgegenüber legt der Autor auf Grundlage seiner narratologischen Analyse dar, dass die Evangelisten das Repertoire an Reaktionen kreativ und variantenreich einsetzen. Einzelpersonen und Gruppen der jeweiligen Perikopen werden durch die Vielfalt an Reaktionen positiv oder auch negativ charakterisiert, teils in recht komplexer Art und Weise; in den einzelnen Episoden wie auch in der Gesamterzählung werden damit Handlungen vorangetrieben. Weil die Evangelien auf einen gemeinsamen Bestand an Reaktionen auf Wunder zurückgreifen, legt sich nach Kiffiak nahe, dass hinter den Wundergeschichten mündliche Überlieferungen stehen, die auf die frühen Anhänger Jesu in Galiläa bzw. Judäa zurückgehen.

Jordash Kiffiak Born 1977; 1998 BA in European History; 2004 MA in Religious Studies; 2015 PhD in Comparative Religions from the Hebrew University of Jerusalem; since 2007 teaching Hellenistic Greek and biblical Hebrew; since August 2015 postdoctoral researcher at the University of Zurich.
Jetzt bestellen:

https://mohrsiebeck.com/buch/responses-in-the-miracle-stories-of-the-gospels-9783161542206?no_cache=1 order@mohrsiebeck.com

Telefon: +49 (0)7071-923-17

Telefax: +49 (0)7071-51104 